\title{
LVIII. Observations on magnetic substances
}

\section{Mr. David Lyon}

To cite this article: Mr. David Lyon (1834) LVIII. Observations on magnetic substances, Philosophical Magazine Series 3, 5:30, 415-418, DOI: 10.1080/14786443408648498

To link to this article: http://dx.doi.org/10.1080/14786443408648498

册 Published online: 01 Jun 2009.

Submit your article to this journal 준

Џ Article views: 2

Q View related articles $₫$ 
That some oxide of nitrogen, which in the present state of our knowledge of that class of compounds seems to be the nitrous acid, is capable of rendering phosphuretted hydrogen spontaneously inflammable, when that oxide is present to the extent of one ten-thonsandth part of the volume of the gas:

That such gas has a general resemblance to phosphuretted hydrogen as obtained in the spontaneously inflammable state by ordinary processes, which last probably owes its ready accendibility to the presence of an equally minute trace of a volatile compound of phosphorns and oxygen, analogous to nitrous acid.

LVIII. Observations on Magnetic Substances. By Mr. David LYon.*

IRON was for a long space of time the only substance which was known to be capable of exhibiting magnetic phænomena. It was afterwards found that two other metals, nickel and cobalt, are endowed with a similar capacity.

Hence it appears that magnetism is not a peculiar essence of one particular substance only; and that whatever be its nature, it is not confined to one substance alone, but is common to different chemical elements. It may, therefore, be properly inquired, whether in any principal qualities, or in the numerical values of qualities, these elements do resemble one another, and are likewise distinguishable from all the other elements. For if such be the case, we may come to know on what magnetism depends, or in other words, to account for its presence in these elements and in no other; although we do not enter upon the question, as to what magnetism really is, or what is its physical origin.

The atomic weights of the three magnetic elements, as stated by Berzelius, are as follows :

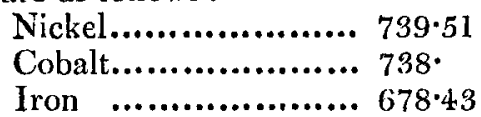

The specific gravities, as stated in Pouillet's Elémens de Physique, are,

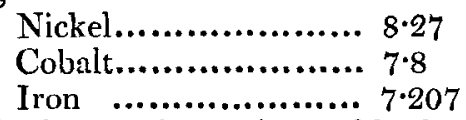

Thus, both in the atomic weights and in the specific gravities, we observe that the three magnetic substances or elements have values near together: and on inspecting the values of all the chemical elements, we observe further, that there is no

* Communicated by the Author. 


\section{Mr. Lyon's Observations on Magnetic Substances.}

other element whose values come very near or fall within those of the three magnetic elements. This is a fact or observation which appears hitherto not to have been brought forward, but which is certainly deserving of notice, both for itself, and for the considerations to which it may lead.

If, for the several chemical elements, we divide the specific gravities by the atomic weights respectively, we shall obtain a series of numbers, which are the relative numbers of atoms of the several elements contained in a given space or volume. In this way, and making use of the values stated above, we have for the three magnetic elements:

\begin{tabular}{llcccc}
\multicolumn{3}{c}{ Specific Gravity. } & Atomic Weights. & $\begin{array}{c}\text { Atoms contained } \\
\text { in a given space. }\end{array}$ \\
Nickel...... $8 \cdot 27$ & $\ldots$ & $739 \cdot 51$ & $\ldots$ & 1118 \\
Iron ...... & $7 \cdot 207$ & $\ldots$ & $678 \cdot 4.3$ & $\ldots$ & 1062 \\
Cobalt...... & $7 \cdot 8$ & $\ldots$ & 738. & $\ldots$ & 1057
\end{tabular}

It will scarcely need to be noted, with reference to this calculation, that we are at liberty to remove the decimal points, provided it be done uniformly for all.

On considering the two series, $i$.e. the atomic weights and the ratios of atoms contained in a given space, respectively, for the several chemical elements, we shall be conducted to speculations relative to the atomic bulks; or in other words, to investigate what may be the relative bulks or sizes of the solid nucleus of the atoms of the several elements. But for our present purpose, still attending solely to the three magnetic elements, when we consider the approximation of their numbers in these two series, there appears no ground for hesitation in allowing that their atomic bulks must be but little different from one another.

We come then to the conclusion that the values of the atomic weights, and likewise of the atomic bulks of the three magnetic elements, are near together*. And we shall find further, that no other element approaches them in both these

* The atomic weights stated above are those published by Berzelius in his Essai sur la Théorie des Proportions Chimiques, and copied in the fifth edition of Thénard's Traité de Chimie. In a subsequent list, published by Berzelius in the Annales de Chimie et de Physique, tom.xxxviii. (1828), and copied in Dr. Daubeny's Introduction to the Atonic Theory, some modifications are made in the atomic weights. The metals generally have numbers assigned to them, which are one half of those in the former list. But they have not all been so reduced; there are exceptions in some few in. stances. Now according to this later series, it is further remarkable, on forming as above indicated a table of the numbers of atoms contained in a given space, that of all the chemical elements, with the exception of carbon, the three magnetic elements and copper are those which have the greatest numbers in that table. 
respects. And are not these two qualities the principal (if not the only) primary qualities which belong to atoms, and may be different in value for the different chemical elements?

May it not be hence inferred, that the power or liability to manifest the magnetic phænomena,-being peculiar to, or most observable in, certain elements, and them only,-is dependent upon the values of those two qualities in their atoms? But what the particular nature may be of the connexion binding the magnetic phænomena to such elements as have values of the two qualities at or near to the mean of the values of the three elements, iron, nickel, and cobalt, may be the subject of further research.

It will thus be observed that in inquiries into magnetism we may distinguish two parts, independent of each other : 1 st, the nature of the nagnetic substance; 2nd, the nature of the magnetic phænomena, or the real source of their production, and the description of the minute and latent modes of the phænomena themselves. What has been adduced above, relates solely to the former of these parts.

With regard to the latter, and chiefly for the sake of its bearing upon the inference or view above proposed, it may be well to state that 1 have been engaged in an investigation, which appears to me to disclose the origin or fundamental principle of the phænomena of terrestrial magnetism. It may be added that the original idea of this investigation occurred to me, and was pursued some time previously to either of the inquiries relative to magnetism. Not knowing, however, whether my present communication will be permitted to appear in the pages of the Philosophical Magazine, and also on account of the additional space, and the diagrams that would be required for the development of my views on this subject, the exposition of the same must be deferred for another communication.

For the reason before mentioned, I still think it will be of service to give a brief notice thereof, and have accordingly drawn up the subjoined queries for that purpose.

Whether, in considering more rigorously the principles applicable to the rotation of the globe, i. $e$. on examining more minutely into the actual path of translation of the atoms, there may not be found the origin or real source of production of the phænomena of terrestrial magnetism; it being conceived that this path is not represented in its ultimate form by the theory which lays it down as being a circle.

And whether the discussion of this matter will not more immediately (and previously to or apart from any discussion of the agency of an æther, or of the consequences of the hetero-

Third Series. Vol. 5. No. 30. Dec. $1834 . \quad 3 \mathrm{H}$ 
geneity of atoms in the globe,) afford the natural interpretation of the law or formula of the magnetic dip or inclination deduced by Messrs. Biot and Kraft from data of observation, viz. that for any given latitude, the tangent of the inclination is to the tangent of that latitude as $2: 1$.

If it can thus be shown that the fundamental principle of terrestrial magnetism is necessarily connected with the path of an atom, considered in a system homogeneously composed, then with regard to the various chemical elements or species of atoms composing the mass of the earth, the greater part of which do not exhibit the magnetic phænomena, it would remain to be examined in what manner, or by what circumstance, dependent upon the respective values of the two atomic qualities before mentioned, the atomic paths of the greater number are so far modified (from what may be called the type, preserved in the magnetic elements, ) as not to present the (magnetic) phanomena in the same sensible way as the three elements, iron, nickel, and cobalt.

In counexion with the foregoing investigations would come another: whether, in general, the physical and chemical properties of the several chemical elements or species of atoms may not depend upon the respective values of the atomic weights and atomic bulks. And here it may be remarked with respect to the magnetic elements, and the approximation in their values of the two qualities, that besides the circumstance of their being magnetic, there are also to be observed many marked analogies in their physical and chemical properties; these analogies being, without doubt, greater than what are to be found in the case of any two or more of the other chemical elements.

Liverpool, April \&2, 1834.

LIX. Description of a Thunder-Storm as observed at Woolwich; with some Observations relative to the Cause of the Deflection of Electric Clouds by high. Lands; and an Account of the Phanomena exhibited by means of a Kite elevated during the Storm. By W. Sturgeon.*

ON Saturday evening, (June 14th,) about 8 o'clock, an electric storm passed partly over this place, exhibiting lightning the most splendid ever beheld. The wind was pretty brisk from $S$. by $W$. about the first appearance of the storm, and if the electric clouds had obeyed the force of the wind only, the principal part of them would have come directly over us. This, however, was not the case, for instead of their being

* Communicated by the Author. 